\title{
COVID-19 Emergency eLearning and Beyond: Experiences and Perspectives of University Educators
}

\author{
Andre Matthias Müller ${ }^{1, *(\mathbb{D}}$, Charlene Goh $^{2} \mathbb{D}$, Li Zhen Lim $^{2} \mathbb{D}$ and Xiaoli Gao ${ }^{1,2, *}$ \\ 1 Saw Swee Hock School of Public Health, National University of Singapore, Singapore 117549, Singapore \\ 2 Faculty of Dentistry, National University of Singapore and National University Health System, \\ Singapore 119085, Singapore; charlene.goh@nus.edu.sg (C.G.); denllz@nus.edu.sg (L.Z.L.) \\ * Correspondence: ephamm@nus.edu.sg (A.M.M.); dengx@nus.edu.sg (X.G.)
}

Citation: Müller, A.M.; Goh, C.; Lim, L.Z.; Gao, X. COVID-19 Emergency eLearning and Beyond: Experiences and Perspectives of University Educators. Educ. Sci. 2021, 11, 19. https://doi.org/10.3390/

educsci11010019

Received: 30 November 2020 Accepted: 23 December 2020 Published: 5 January 2021

Publisher's Note: MDPI stays neutral with regard to jurisdictional clai$\mathrm{ms}$ in published maps and institutional affiliations.

Copyright: $(2021$ by the authors. Licensee MDPI, Basel, Switzerland. This article is an open access article distributed under the terms and conditions of the Creative Commons Attribution (CC BY) license (https:// creativecommons.org/licenses/by/ $4.0 /)$.
Abstract: Due to the COVID-19 pandemic, eLearning became the lifeline of higher education. We explored university educators' eLearning perspectives, practices, and future adoption intentions. In-depth interviews with 14 educators from a large university in Singapore were conducted. Educators had limited eLearning experience prior to COVID-19 emergency eLearning and expressed strong preferences for in-person sessions. The short notice to switch to eLearning and lack of eLearning experiences created stress and anxiety. Educators responded by making efforts that allowed for teaching to continue, conceding that some expectations had to be readjusted. Despite many obstacles, educators acknowledged reduced apprehension towards eLearning. Reflecting upon their experiences, educators highlighted opportunities and challenges of eLearning. A key opportunity was increased flexibility, which enabled students to learn independently. Additionally, eLearning triggered reflection upon educators teaching which could lead to improved practice. Reduction of some barriers to student-educator interaction were also mentioned. Key challenges include creating social, emotional, and cognitive engagement, catering to diverse student needs and providing holistic learning experiences. Considering opportunities and challenges, educators envisioned that eLearning would feature in their future teaching if practical and helpful for achieving educational goals. Hybrid or blended learning approaches were preferred, but support enabling the implementation of technology-based and pedagogy-informed teaching is necessary.

Keywords: blended learning; COVID-19; emergency e-Learning; e-Learning; higher education; hybrid learning

\section{Introduction}

The COVID-19 pandemic has seen many global universities re-engineering their teaching activities. While eLearning was previously seen as an optional or potentially fashionable way to deliver lectures, conduct tutorials, and provide skill training for interested educators [1], it became the lifeline for higher education during the COVID-19 pandemic [2]. In fact, eLearning efforts in the university setting are not new and some inductions have been offered [3]. However, the recent pandemic-related measures forced many institutions to accelerate the development as well as the deployment of technologies and the related infrastructure to remove basic Level-1 barriers and embark on eLearning swiftly [2,4]. The pandemic response also involved offering courses to support educators in the adoption of online teaching technologies and strategies to enable the continuation of teaching and learning with reasonable quality $[2,5]$. The rapid move to eLearning due to the pandemic is commonly referred to as emergency eLearning which, in comparison to purposefully developed eLearning efforts did not undergo structured long-term planning [6].

Such rapid developments also occurred in densely populated Singapore, which recorded its first COVID-19 case on 23 January 2020, leading to the implementation of various public health measures [7]. As in many countries, university campuses have been 
identified as high-risk areas for community transmission [3]. This risk is especially high during traditional face-to-face teaching due to extended, close physical contact among many people [8]. In an effort to mitigate infection risk, universities either closed down entirely or tightly controlled the number of people on campus. As a result, eLearning quickly became the primary mode of instruction. Although in Singapore, the number of infections peaked in April and May of 2020 and has declined significantly over time, many teaching activities continue online to minimize the risk of infection and another outbreak. Similar approaches have been adopted by many universities around the globe $[2,3]$.

As many university leaders have thought about eLearning and invested into building a supportive infrastructure prior to the pandemic $[1,9]$, it is not surprising that the recent developments were perceived as an opportunity to move the eLearning agenda forward. This is especially evident in Singapore where digitalization is a core aspect of development, and household Internet access is high [10]. However, with the technology and infrastructure in place, university teachers are key to making eLearning a major element of tertiary educations, as they are the ones to implement it. The current situation presents an opportunity to explore the experiences, perceptions, practices, and future adoption intentions of tertiary education teachers towards eLearning. This is so because most educators, irrespective of teaching preference, have likely conducted eLearning during the pandemic. In contrast to the abundant literature on learners, the experiences and perspectives of those who educate, train, and mentor have received relatively little attention with most studies investigating eLearning as an adjunct to traditional face-to-face teaching [9] or narrowly focusing on educators' acceptance and adoption of technology [11-13]. The majority of these studies also mainly comprised educators who had some interest in or prior experience with eLearning. However, it is important to understand how the full-spectrum of university educators view eLearning, how they approach it and what challenges as well as opportunities they perceive. In addition, it is crucial to understand their continued-use intentions beyond COVID-19-related emergency eLearning [2] when onsite instruction can resume. These insights, currently widely absent from the literature, will be invaluable when planning further investments into the creation of eLearning ecosystems [6].

We conducted qualitative research to explore experiences, perceptions, practices, and future adoption intentions related to eLearning of educators from a large public university in Singapore. In the following sections, we will introduce the methods we employed to achieve this aim before highlighting the results of our qualitative analysis. The findings will be contextualized in the last two sections.

\section{Materials and Methods}

This work is part of a larger study on eLearning perspectives of tertiary education teachers-another part on dental educators is forthcoming. To openly explore university educators' experiences, perspectives, practices, and future adoption intentions related to eLearning, we adopted qualitative research methods, employing in-depth interviews and thematic analysis. The study was conducted from 13 May to 3 July 2020. All study procedures were approved by the Saw Swee Hock School of Public Health Departmental Ethics Committee (SSHSPH-016) prior to commencement of data collection. The 32-item Consolidated Criteria for Reporting Qualitative Research (COREQ) checklist [14] was used to guide the reporting of our study.

\subsection{Participant Recruitment and Setting}

We purposely recruited faculty members of the Saw Swee Hock School of Public Health, at the National University of Singapore. Faculty members were eligible if they: a) had teaching responsibilities in an undergraduate module after 7 February 2020 when physical distancing measures were introduced and b) had to convert at least one undergraduate physical session into an eLearning session due to these measures. This ensured we only recruited faculty members with relevant experience. Potentially eligible staff received informal email invitations outlining study aims and procedures, and stating in- 
clusion criteria. Faculty members who were eligible and willing to take part received a formal email invitation which included the Participant Information Sheet, Consent Form, and a demographic questionnaire. We scheduled interviews following the receipt of the completed documents. No reimbursement was provided.

\subsection{Data Collection}

Data were collected through in-depth interviews. Participants were interviewed in English by the first author, a PhD holder with qualitative research experience. Due to the COVID-19-related physical distancing measures, interviews were conducted via Zoom, a cloud-based videoconferencing service [15] which has been used successfully in previous qualitative research [16].

An interview guide was developed and iteratively refined by all authors following pilot testing which involved interviewing one person with relevant background. Refinements were made throughout data collection to explore emerging topics not covered in earlier iterations. The interviewer first reiterated the purpose of the study, obtained a final verbal consent, and answered questions before commencing with the interviews. Openended questions and prompts were used to explore experiences and perceptions related to eLearning, eLearning practice, eLearning-related opportunities and challenges, as well as support needs, and future eLearning adoption intentions. Interviews were recorded in full using Zoom's inbuilt audio-recording features. In addition, field notes were taken during and shortly after the interviews.

\subsection{Data Analyses}

Verbatim interview transcripts were automatically generated by Zoom. However, substantial editing was necessary due to inaccuracies in the speech-to-text conversion. A student transcriber reviewed and edited all transcripts based on the audio recordings, and the first author carried out accuracy checks. Resulting transcripts were used for analysis. In addition, field notes informed our analysis.

Demographic information was analyzed by using means or frequencies as appropriate. Thematic analysis was applied to the data [17]. To allow for inter-coder reliability, two authors (AMM \& XG) read the transcripts and conducted line-by-line coding of three transcripts together. After this, the first author proceeded to code on his own. Broad analytical categories were established at the beginning and iteratively refined, while themes and subthemes were developed inductively (which means they were developed based on the data and not based on pre-conceived ideas). Final themes and subthemes were agreed upon, and representative quotes were chosen for illustration. We also attempted to identify deviant cases that did not fit the overall trend of the data to understand the limits of our data and to ensure all relevant data were included. No such cases were identified. To protect confidentiality and for referencing purposes, we used unique identifiers for each participant. All analyses were carried out using Microsoft Word and Excel, and we invited participants' feedback on the findings.

\section{Results}

Of 16 eligible faculty members, $14(87.5 \%)$ were recruited and interviewed. Interview lengths ranged from 34 to $77 \mathrm{~min}$ with a mean of $53 \mathrm{~min}$ (Standard Deviation $=12.3 \mathrm{~min}$ ). Participant characteristics are displayed in Table 1. Data saturation was reached after 11 participants.

We grouped the findings into five topic categories: eLearning experience prior to COVID-19 physical distancing measures, eLearning during COVID-19 physical distancing period: Emergency eLearning, Opportunities of eLearning, Challenges of eLearning, Future eLearning adoption. Where appropriate, we derived themes and subthemes to organize the findings in each category (Figure 1). 
Table 1. Participant characteristics.

\begin{tabular}{|c|c|}
\hline Variables & Values \\
\hline \multicolumn{2}{|c|}{ Age in Years } \\
\hline Mean & 43.43 \\
\hline SD & 11.60 \\
\hline Range & $32-67$ \\
\hline \multicolumn{2}{|c|}{ Sex } \\
\hline Male & 8 \\
\hline Female & 6 \\
\hline \multicolumn{2}{|c|}{ Highest Academic Degree or Qualification } \\
\hline $\mathrm{PhD} / \mathrm{MD}$ & 12 \\
\hline Masters & 2 \\
\hline \multicolumn{2}{|c|}{ Years of Tertiary Teaching Experience } \\
\hline Mean & 9.17 \\
\hline SD & 10.19 \\
\hline Range & $1-33$ \\
\hline \multicolumn{2}{|c|}{ Prior eLearning Use } \\
\hline Often/very often & 0 \\
\hline Sometimes & 4 \\
\hline Rarely & 6 \\
\hline Never & 4 \\
\hline \multicolumn{2}{|c|}{ Self-Reported Information Communication Technology Skills } \\
\hline Advanced & 2 \\
\hline Intermediate & 5 \\
\hline Basic & 7 \\
\hline Novice/non-existent & 0 \\
\hline
\end{tabular}

\section{1. eLearning Experience Prior to COVID-19 Physical Distancing Measures}

Prior to COVID-19 physical distancing measures, educators had limited or no experience with eLearning in their teaching. Participants mentioned that the default mode was conducting onsite sessions. However, some also shared that the University occasionally promoted eLearning. An educator explained that following the SARS (severe acute respiratory syndrome) pandemic in 2003, the University implemented an eLearning week during which teaching and learning only occurred online, mainly or exclusively in an asynchronous manner through pre-recorded lectures or sharing of online material (Interviewee 8). Another educator suggested that this was a 'good entry point to the whole system' (Interviewee 9). However, due to the participants' preference for onsite teaching only a few made eLearning efforts.

\section{2. eLearning during COVID-19 Physical Distancing Period: Emergency eLearning}

Physical distancing measures were implemented halfway through the second semester in February and March 2020, mandating all classes to be conducted online. Educators shared how they felt about moving online, how they approached teaching and assessments, and what their experiences with emergency eLearning were. 


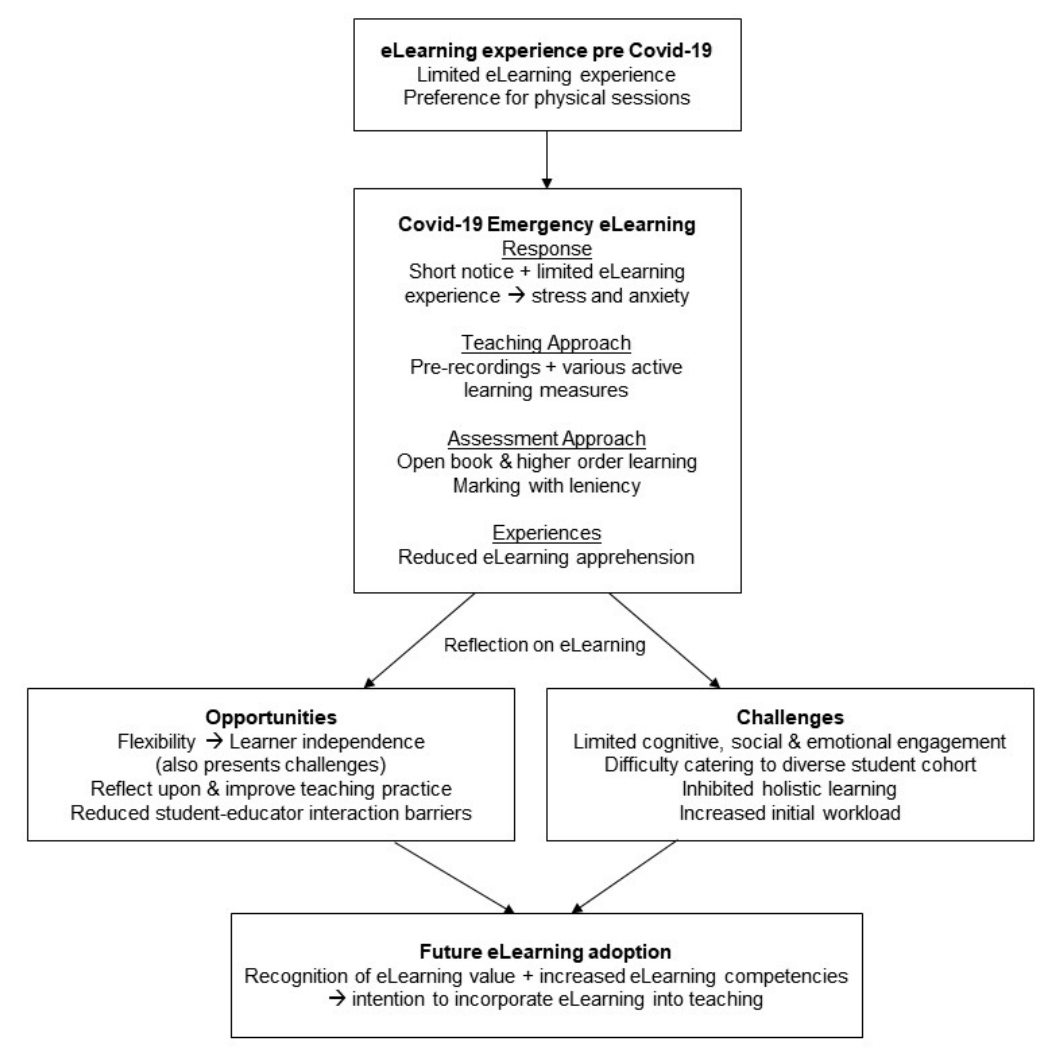

Figure 1. Visual summary of the study results (developed by the authors).

\subsubsection{Immediate Response: Short Notice to Get Things Up, No Matter What}

Educators who coordinated their own modules shared that the mandatory shift to eLearning came rather suddenly, with some explaining how this created stress, uncertainty, and anxiety. This was compounded by the internal struggle to move away from default physical classes, and by having to use unfamiliar technologies. For example, a participant shared how he was very used to physical classes and changing this mind-set and getting used to online tools was difficult (Interviewee 10). Another participant highlighted her preference for traditional onsite classes, and described how learning new things such as recording lectures induced 'techno stress' (Interviewee 8).

However, the short notice compelled educators to react fast and most focused on ensuring that teaching continued, even if it meant readjusting expectations. As a participant put it '.. . the current situation was very rushed, uh, at very last minute. So, it was really firefighting and troubleshooting and sort of tying loose ends and cutting corners and trying to get it up as efficiently as we can' (Interviewee 1).

\subsubsection{Approaches to Teaching and Assessment}

A priority was to ensure students had access to important content that would normally be delivered during onsite lectures. A common approach was to use some form of prerecorded material, such as webcasts from previous semesters that could be uploaded to the learning management system. Some expressed that it gave them some relief as it allowed for a reasonably 'seamless switch' (Interviewee 9) to online content delivery. To enable discussion and reflection which normally took place during onsite tutorials, different approaches were taken. These included uploading of additional material and provision of prompts for reflection, creating thematic forums, and conducting synchronous sessions using Zoom.

While some educators stuck to their initial approach to conducting eLearning, others went through an iterative process to improve the student experience and ensure learning takes place. Although such adaptations were considered important, a participant expressed 
discomfort with this approach by saying the following: '.. we really had a tough time ... It was literally like running a guinea pig session.... So, it really was taking a risk and try it as we go along' (Interviewee 3).

In terms of assessment, educators made adjustments. For written tests and exams, various forms of open-book assessments were adopted as suggested by the University. It was also recommended to focus on higher-order learning and real-world application during these assessments to safeguard against dishonesty. However, some educators were concerned about integrity and conducted proctoring using Zoom.

And I have to monitor their so-called behavior and actions or activities through the Zoom monitoring screen. And of course, with the support of the other executives from the Educational Office to supervise them, invigilate them, make sure they don't do anything funny. (Interviewee 14)

Although the primary objective of all assessments remained to gauge how well students achieved learning outcomes, educators spoke about considering the multifaceted impact of the pandemic on students. This empathy and resulting assessment adjustments were described as follows:

Because of the online learning, less in-person tutoring. And also, because some of the students were very stressed because of the COVID-19, they were quarantined or their parents lose their job. There were so many other problems, you know. So, I said maybe we should consider that in the marking. And given all these constraints, maybe we can be a bit more lenient. (Interviewee 8)

\subsubsection{Experiences with Emergency eLearning}

Reflecting about their emergency eLearning experiences, educators expressed that interaction was a key challenge. They spoke about how they were unsure about student engagement and learning because of limited interaction. Although attempts were made to interact, educators felt they rarely knew how students were doing. An educator voiced his frustration by saying ' ... even though I try to engage them and ask them to speak up, I ask them to ask questions, I ask them to type in questions, ... but we don't really see them asking questions' (Interviewee 10).

On the other hand, educators also suggested that their initial eLearning apprehension reduced over time because they gained more confidence in using the different technologies, and because they felt students performed reasonably well. Different explanations were offered for this, including that during the physical distancing period students were not distracted, and could hence focus and reflect better. Some also mentioned the administrative and training support they received from the School and the University was helpful. Although educators still expressed a strong preference for in-person sessions, some highlighted valuable learning points.

\subsection{Opportunities of eLearning}

Based on their overall experiences and reflection, educators spoke about opportunities and challenges of eLearning. In terms of opportunities, three themes were apparent: flexibility enables independent learning, reflection upon and improvement of teaching practice, and overcoming some barriers to student-educator interaction.

\subsubsection{Flexibility Enables Independent Learning}

Educators mentioned that eLearning is more flexible than onsite teaching. As teaching and learning can take place at any location and any time, some barriers are removed. For example, educators mentioned that there is no need to travel to and from campus. This allows students and educators to choose a conducive environment which saves time and energy for those living far away. These advantages are especially pronounced for asynchronous lecture-style content delivery sessions. Educators said that introducing concepts and ideas could be done via pre-recorded videos as it is likely to be similarly 
effective as in-person classes. A participant explained that such an approach to content delivery can improve quality and consistency, as educators can record lectures when they are 'switched on' (Interviewee 5).

Educators also explained how the increased flexibility meant that students have more independence over their learning. They said that it enables students to learn based on their preferences and needs. For example, considering pre-recorded lectures, an experienced educator said:

So, if everything's so factual - all the technical terms you have to use - if we give it in class, it's so boring. ... I guess the eLearning allows the pace to be adapted to the learning capability of the student. Student has the freedom of choice to decide, "oh, it's very easy. I'll skip to the next one". A slower student can spend more time thinking about it. (Interviewee 8)

Also, compared to onsite sessions there is reduced pressure to actively take part in synchronous sessions, further enabling students to decide on a preferred learning approach This increased independence was seen as an advantage. However, some educators voiced concerns that learning outcomes can be too student-dependent when conducting eLearning. Specifically, they spoke about how students may underestimate the difficulty of learning online because of their confidence in using technology. Some mentioned that students have not learned how to learn online, and said that it is difficult. Educators explained that, with reduced contact hours and less structure, students need to be more proactive to reach out to educators for support and to feedback on how their teaching could be improved, and ensure they progress their own learning. An educator summarized this notion as follows: 'It's going to take a lot of discipline. Discipline, motivation, struggles' (Interviewee 7). Some educators suggested providing students with guidance on how to navigate their eLearning.

\subsubsection{Reflect Upon and Improve Teaching Practice}

There was a strong sense that, despite the preference for onsite teaching, eLearning presents an opportunity to reflect upon and improve teaching practice. Educators talked about how, when they taught a module for a long time, they 'got stuck in a certain way'(Interviewee 13) or were in 'auto-mode'(Interviewee 10). The eLearning mode makes them think about their teaching objectives and the strategies to reach them.

Some explained how eLearning facilitates thinking about how to engage students, be clearer when explaining concepts, design learning activities, present and scaffold learning, and set assessments that require higher-order thinking. Speaking of producing pre-recorded lectures, an educator said:

... to put it on video, you need to crystallize things. So, you take more effort in terms of preparing. And you will have to script it properly and think through very carefully. "Is this an unnecessary phrase? Is this a distracting phrase? Is this sentence really necessary?" So that takes up a lot of time, but actually personally, I think improves the quality a lot. (Interviewee 12)

Some even mentioned that eLearning motivated them to try teaching strategies they wanted to implement for a long time, such as blended learning. Finally, educators talked about how eLearning triggered their creativity (e.g., use of various technologies) which they thought would benefit their teaching development.

\subsubsection{Overcoming Some Barriers to Student-Educator Interaction}

Some educators highlighted advantages in terms of student-educator interaction when conducting synchronous eLearning. They explained that local students are often shy during in-person sessions. As such, they tend to minimize interactions with educators during class in an effort to avoid exposing some form of inadequacy publicly. Educators said that synchronous Zoom sessions made some students overcome this barrier. Using the chat function, they showed more openness about not understanding certain concepts and 
topics, and asked more questions compared to physical classes. An educator explained it as follows:

... I feel that because they have access to the chat function. ... They would now ask these questions using the chat function. And they were quite open about it. So, for example, they would say things like, "oh, I'm so blur about this". So, they were quite open about how they felt about understanding the concept. ... It was really strange in some ways that having this physical barrier, other barriers were broken in a way. (Interviewee 9)

\subsection{Challenges of eLearning}

Educators mentioned a number of challenges when conducting eLearning, which were organized into four themes: engagement struggles, difficulty in catering to students' needs, inhibiting holistic learning, and educators' workload.

\subsubsection{Engagement Struggles}

Educators explained that their main eLearning challenge is related to student engagement. Broadly speaking, engagement can be categorized into different interrelated domains including social, cognitive, collaborative, emotional, and behavioral [18]. Educators spoke about difficulties to gauge and promote engagement in different domains.

Cognitive and Collaborative Engagement: Educators talked about how difficult it is to gauge cognitive engagement when conducting eLearning. Some attributed this to the complete or partial absence of non-verbal cues that they use during onsite sessions to understand where students are in their thinking and learning, which then informs the decision of whether intervention is necessary. They spoke about what can be observed during live eLearning sessions is limited, as many students do not turn on their camera, and even if they do, many of their expressions are impossible to capture. As a result, there is limited feedback educators can work with to adjust their teaching instantaneously. This is even more problematic for asynchronous sessions where there is no live feedback. As such, educators are left to wonder how cognitively engaging their asynchronous learning material and activities are. Some voiced their frustration by saying that they do not know how students engage with material they provide, and that in the physical classroom this was somehow observable. An educator explained it as follows:

Whereas in a classroom situation, I look at you. I see you confused. You can't hide that. Your response is in my face, right. I can therefore, repeat myself. I try to repeat, because I think this is a difficult concept. I don't think you are getting it. Let me try and repeat to the class.... So, there is that kind of things that actually got lost'. (Interviewee 12)

In addition, educators talked about the value of having students meet physically to interact, discuss, and collaborate. During such sessions, educators can provide spontaneous support. Although synchronous Zoom meetings are a viable way to interact, educators expressed doubt whether high collaboration quality can be achieved.

Social and Emotional Engagement: Educators also explained how the physical presence in the same learning space is important for connecting and building bonds which facilitates the creation of a socially and emotionally engaging learning atmosphere, and how this cannot be replicated via eLearning. Some spoke about how just speaking to individual students and connecting on a more personal level can positively affect learning attitudes and increase interest in learning, while others described how they value connecting to students to understand how their teaching fits into the big picture of their lives. They described that eLearning is often less personal, and interactions are mainly 'utilitarian' and 'much more goal-driven' (Interviewee 9) which can inhibit motivation of students and educators alike. An educator explained: 'Because when you have a group of students looking at you, you get a feeling that they, you want to give more, but without that face-to-face thing, you don't have that. So, I really think it's a pity' (Interviewee 7). 
However, educators also talked about how engagement could be promoted. Various ways to foster cognitive engagement with learning material were brought up, such as introducing essays that are meant to make students address more real-life problems, and integrating quizzes and videos into pre-recorded lectures. Some said their main avenue to steer engagement was via synchronous Zoom sessions. They mentioned devising specific strategies to promote the use of the chat function, using break out rooms and incorporating live polls. An educator described how he arranged his work station to be able to look into the camera when lecturing so that students feel he is directly talking to them as a way to make a social connection. Others talked about sending more emails, setting up forums, offering more consultations, and/or giving more feedback. Nevertheless, educators maintained the view that these measures are inferior in terms of creating meaningful engagement, and highlighted a need for at least some in-person contact.

\subsubsection{Difficulty in Catering to Students' Needs}

Educators also voiced that it is challenging to understand and cater to the needs of a diverse student cohort. They specifically spoke about two aspects that they feel are difficult to address.

Uneven Playing Field: Despite the cited potential of eLearning to provide a level playing field for all students, educators raised concerns about whether all students are indeed equal when teaching is primarily conducted online. Some questioned whether all students have access to conducive working environments, technologies such as adequate computers, a camera, and reasonably fast and stable internet. An educator reflected about his experience:

And so, with everything virtually online, the question is that are all students on equal playing field, you know. It may not be. So, then those students who cannot afford certain things-a fast laptop or a good Wi-Fi or fast bandwidth internet, or something ... it may not be fair across the board for all students in terms of their learning. ... So, I would think that there there'll be a limitation because the assumption of going online is that everybody is on the same playing field, but it's not true. (Interviewee 11)

Others talked about students having different learning needs and that spontaneous support online is more difficult to provide for students who struggle. While educators expressed a certain helplessness around issues of eLearning access and resources, some mentioned considering these when planning their teaching and assessment. Common strategies to address the different student needs mentioned by educators include recording synchronous Zoom sessions, providing more time to complete tasks, offering various assessment options, and extending time windows during which tests could be completed (e.g., 24-h windows to complete open-book tests).

Student Workload and Capacity: Educators also spoke about how they are concerned about student workload and coping capacity. Students could be overloaded by material as it is easy to upload resources that might be interesting but not essential. Some said that students are likely not equipped to disentangle which materials are important for their learning, and might feel overwhelmed by the amount of content they believe needs to be covered. Others spoke about how the more independent learning required when conducting eLearning will increase student workload, as they have to acquire skills and knowledge with reduced support. Finally, some explained that the ambition of educators to innovate to foster engagement can overburden students. An educator explained it like this:

So, I can imagine that if I'm a student and that my lecturers are using different platforms in different ways. Someone use blogs, someone use a forum, someone use this, and then I have to navigate. No matter how savvy I am, right, every module is a little bit different ... I'm one lecturer like 10 extra start using innovation ... it just clouds, the whole thing. And I'm not sure if that actually helps learning. (Interviewee 11) 
To address student workload, educators talked about the importance of proper planning that involves considering pedagogical principles such as constructive alignment, but acknowledged that it is difficult to know how students feel and suggested evaluating this in detail.

\subsubsection{Inhibiting Holistic Learning}

Educators spoke about the importance of holistic learning and development when students attend university. They explained that academic and non-academic skills and competencies ought to be part of a rounded tertiary education. In terms of academics, educators mentioned that more practical and applied learning experiences that are commonly gained during onsite sessions are difficult to translate into an online environment. For example, role plays, debates, field visits, and some experimentation are almost impossible to implement through eLearning. An educator suggested that such experiences would then not be offered, placing students at a disadvantage.

Beyond academic skills and competencies, educators repeatedly talked about the importance of the less tangible outcomes of a tertiary education such as personal growth, building social networks, working in teams, and acquiring interpersonal skills. These were seen as distinguishing a university education from solely taking online courses, and were often obtained through co-curricular activities, campus living arrangements, and shared experiences. An educator explained the way such outcomes can be achieved through eLearning receives little attention: 'We have been focusing more on how do we deliver lectures, tutorials, and all that; ... there are other elements of the students' academic life ... that we should not forget' (Interviewee 4) Another educator bluntly asked: ' . . . how do you transfer the intangibles?' (Interviewee 11), and concluded that it is likely impossible without onsite sessions.

\subsubsection{Educators' Workload}

Due to the mentioned challenges, educators described the increased time and effort required to plan good quality teaching. Some emphasized the importance of re-assessing learning objectives and reworking large portions of their teaching to align it with the refined objectives, the affordances of eLearning, and different needs of students.

A huge contributor to the increased workload is creating pre-recorded lectures. Some explained they need to crystalize content, draft a script, record a video, and edit it. As such, the process is ' ... much more complicated than just preparing slides and then teaching it' (Interviewee 7). Other elements of teaching were also quoted as increasing workload, mainly assessments and marking due to the shift to assessing higher-order learning. Also, the limited ability to observe students during synchronous sessions means that educators need to develop new ways of gauging engagement and constantly monitor various inputs. Some also talked about how it is a lot of work to familiarize oneself with the vast amount of new technologies and potential pedagogics that could be applied. However, some acknowledged that the workload is likely to decrease over time, as they become familiar with the technologies and establish their way of teaching online.

\subsection{Future eLearning Adoption}

Although educators expressed their strong preference for onsite teaching with some eagerly waiting to return to the classroom, they acknowledged that eLearning is likely to play a role in their teaching going forward. Educators mentioned the need to adapt to new styles and ways of teaching to ensure they remain relevant to students and evolving requirements of employers. Considering the opportunities and challenges of eLearning, educators commented that eLearning is neither good nor bad, and eLearning components will be incorporated when it is practical and when it can support educational goals. As such, some said that parts of their teaching are likely to continue online. Others voiced their preference for a blended or hybrid approach to leverage on the strengths of eLearning and onsite sessions, and overcome inherent limitations. Some spoke about asynchronous 
content-delivery style lectures to increase flexibility and foster independent learning, and onsite sessions to interact, bond, and enable the acquisition of various academic and non-academic skills and competencies that are part of a holistic university education. An educator described it like this:

We have the engagement and we have the bonding element from the face-toface elements, and ... we have the greater flexibility and potentially additional interesting content through the online material. So, I think my preference would be for a mixed approach. (Interviewee 15)

Finally, there was some consensus that the pandemic-related situation made educators add eLearning to their teaching tool box with many expressing that they intent to use the newly acquired tools to some degree going forward, while acknowledging that support and incentives are crucial to actualize their intentions.

\section{Discussion}

In this qualitative study, we examined the experiences, perceptions, practices, and future adoption intentions related to eLearning in university educators from a large public university in Singapore. We initially explored educators' eLearning experiences before the COVID-19 physical distancing measures. As reported elsewhere [1,12], educators had limited eLearning experience and expressed a strong preference for onsite sessions. Some mentioned that the university implemented eLearning weeks following the SARS outbreak in order to improve eLearning readiness [19]. Nevertheless, with limited adoption of eLearning beyond eLearning weeks, eLearning competency and confidence of educators remained questionable.

Due to limited eLearning readiness, educators felt stressed and anxious when they were forced to rapidly move their teaching online due to the COVID-19 physical distancing measures. This has also been reported in other countries [20]. While the upload of prerecordings provided some relief, facilitating reflection and discussion was difficult. In addition, educators spoke about challenges when assessing students, with some applying leniency, and some implementing stringent measures to maintain integrity. Despite various challenges and a continuing preference for onsite sessions, educators acknowledged a reduced apprehension towards eLearning when they gradually gained confidence.

Three opportunities of eLearning were mentioned by educators. While increased flexibility has been touted as a common strength of eLearning [21], our study provides a more nuanced picture. eLearning-induced flexibility often links to a desirable increase in learner independence (e.g., more freedom to choose when, where, and how to learn) [22]. However, educators cautioned that students may not be adequately equipped to effectively learn online. Although they are well versed in using various technologies, they might not be able to organize their learning without guidance and structure commonly provided via in-person sessions. In fact, constructivism holds that knowledge and skill acquisition does not necessarily occur by simply improving access to information. Educators are key to guide these processes [23]. Evidently, many university students, despite being digital natives, are not prepared for eLearning due to a lack of skills in time management and self-directed learning [24]. As such, providing induction sessions and disseminating guiding material might be warranted.

Educators mentioned that the shift to eLearning also presented an opportunity to reflect upon and improve their teaching. As such, the COVID-19 situation was a critical incident triggering educators to rethink and rework their practice that might have been stagnant for some time. This is significant as university educators who taught a course several times rarely go through the practice-reflection cycle: practice, reflect, implement new practice, reflect [25], thus, inhibiting their teaching development.

A third opportunity of eLearning is the potential of improved student-teacher interaction during synchronous sessions. Although engaging students effectively during eLearning presents challenges, some students who were quiet during onsite classes appeared more active in asking questions and joining discussions in Zoom meetings. This 
finding is intriguing and highlights the diversity of students' needs and learning styles, which should be duly considered by educators.

Educators also highlighted various eLearning-related challenges, a prominent one being engagement. Key to cognitive, social, and emotional engagement are the quantity and quality of interactions. Unfortunately, interactions in online environments commonly lack the transmission of non-verbal cues. This makes it difficult to draw a full picture on how cognitively engaged students are, and to subsequently address engagement. Additionally, building connections and creating bonds, which is important for overall learning engagement, [18] is challenging when conducting eLearning, as interactions are often reduced to subject-related matters. This is problematic as, based on social-constructivist theories, many forms of learning are dependent on experiencing social presence and a sense of community [26]. The socially and emotionally starved learning experiences when conducting eLearning have been discussed in previous research [27]. Challenges around cognitive engagement with learning materials were also mentioned with some educators being unsure how much time, effort, and thought students put into actual learning. To remedy this uncertainty, the validated Online Student Engagement scale (OSE) could be used [26]. As it includes social and emotional engagement into the assessment, it might be a useful tool to inform adaptations to teaching practices.

Educators also mentioned the challenge of catering to diverse students' needs. Particular concerns around equity were mentioned. Despite the expectation that eLearning increases educational opportunities for all students irrespective of background and socioeconomic status, there are significant equity challenges. Students who do not have access to conducive working environments and/or technologies that facilitate eLearning (e.g., reliable Internet) will be disadvantaged [21]. In addition, the pandemic had likely more serious impacts for specific student populations (e.g., drop in household income and added care responsibilities) which might have disadvantaged them further. A study from Canada confirmed that students from disadvantaged backgrounds were adversely affected when emergency eLearning was implemented [20]. Despite educators' attempts to address this (e.g., flexible submission timelines) they felt rather helpless. Institution-level efforts that recognize the diversity of the student cohort in terms of private eLearning infrastructure and opportunities are necessary to enable eLearning equity [28]. Otherwise, institutions risk to reinforce educational inequities that traditionally exist [29]. Related to students' inexperience with eLearning, educators also voiced their concerns around increased student workload. Navigating various technologies, acquiring competencies around independent learning coupled with reduced interactions can challenge students beyond their capacity.

Another challenge is providing holistic learning experiences to students. Although research shows non-inferiority of eLearning compared to in-person teaching when it comes to selective academic competencies [30], how to enable the acquisition of more applied skills such as debating remains elusive [20]. Efforts to transfer practical learning experiences from physical classrooms into digital spaces are being explored by educational technologists in conjunction with educators [31]. Similarly concerning is the difficulty of providing opportunities to attain holistic competencies and values which make a university education whole. Competencies such as establishing social networks and teamwork result, to a large degree, from physical out-of-classroom experiences such as communal living [32]. Also, acquiring tacit knowledge, another pillar of holistic learning, is best facilitated through social interactions in the physical space [23]. With the target of institutions and many educators on improving eLearning to enable student performance, little attention has been paid on how to revive these integral parts of a tertiary education.

Lastly, educators spoke about their future eLearning adoption intentions. Considering their experiences and perceptions, they maintained a preference for onsite sessions. However, the perceived need to adapt to new ways of teaching, the various eLearning opportunities, and the increased eLearning competencies impacted educators' views on eLearning. Implementing some form of blended or hybrid learning was considered desir- 
able as it would allow educators to leverage on the strengths of conducting onsite classes as well as eLearning.

Some limitations of our study ought to be highlighted. First, we only interviewed participants from one department. However, public health education is unlikely to be markedly different in terms of teaching delivery compared to many other subject areas. As such, we do not believe that this has significantly biased the results. Potential bias could have been introduced due to social desirability. Interviewees might have responded in ways that are perceived socially acceptable, and to portray a more favorable picture of their attitudes, practices, and future adoption intentions related to eLearning. However, we employed various techniques to prevent this bias as recommended in the literature [33]. For example, participants were encouraged to share freely and were assured that what they shared would be confidential. Hence, we believe this did not introduce major bias. Finally, power relations might have influenced the interviews. The interviewer is a colleague of the interviewees, some of which are more advanced in their careers. As such, the interviewer might have avoided pursuing certain angles out of concern. However, upon reflection the interviewer does not believe that this played any role in how interviews were conducted and analyzed.

\section{Conclusions}

Following the COVID-19-related emergency eLearning experiences, educators' apprehension towards eLearning reduced. While acknowledging challenges such as engaging students, catering to students' needs, and providing opportunities for holistic learning, they also recognized various opportunities: flexibility that enables independent learning, chances to reflect upon and improve practice, and lowering some barriers to studentteacher interaction. The more balanced view led them to consider incorporating eLearning elements into their teaching even after physical classes can resume, which means tertiary education institutions can expect less resistance and more enthusiasm for eLearning, especially blended and hybrid approaches going forward. Lastly, it appears worthwhile to design educator training that focuses on utilizing synergies between onsite sessions and eLearning to leverage on the best of both teaching worlds. Hybrid approaches, which often involve asynchronous content delivery followed by immersive learning activities during live sessions have received increased attention in recent years, and research highlights promising results [34]. To allow successful and sustainable implementation of hybrid learning, skill trainings, and support will be critical as university educators are likely underprepared [35].

Author Contributions: Conceptualization, A.M.M., C.G. and X.G.; Formal analysis, A.M.M. and X.G.; Funding acquisition, A.M.M.; Investigation, C.G.; Methodology, A.M.M., C.G., L.Z.L. and X.G.; Project administration, A.M.M., C.G. and L.Z.L.; Supervision, X.G.; Writing—original draft, A.M.M.; Writing-review \& editing, A.M.M., C.G., L.Z.L. and X.G. All authors have read and agreed to the published version of the manuscript.

Funding: A.M.M. was supported by the Singapore Ministry of Health's National Medical Research Council, Fellowship Programme by the Singapore Population Health Improvement Centre: NMRC/CG/C026/2017_NUHS.

Institutional Review Board Statement: The study was conducted according to the guidelines of the Declaration of Helsinki, and approved by the Saw Swee Hock School of Public Health Departmental Ethics Committee (protocol code: SSHSPH-016, approval date: 5 May 2020).

Informed Consent Statement: Informed consent was obtained from all subjects involved in the study.

Data Availability Statement: The data presented in this study are available on request from the corresponding author. The data are not publicly available.

Acknowledgments: The authors would like to thank all participants of the study. AMM would like to acknowledge his daughter, Lia Yihan, who reminds him what is important in life.

Conflicts of Interest: The authors declare no conflict of interest. 


\section{References}

1. Tesar, M. Towards a Post-COVID-19 ‘New Normality?': Physical and Social Distancing, the Move to Online and Higher Education. Policy Futures Educ. 2020, 18, 556-559. [CrossRef]

2. Murphy, M.P.A. COVID-19 and emergency eLearning: Consequences of the securitization of higher education for post-pandemic pedagogy. Contemp. Secur. Policy 2020, 41, 492-505. [CrossRef]

3. Sahu, P.K. Closure of Universities Due to Coronavirus Disease 2019 (COVID-19): Impact on Education and Mental Health of Students and Academic Staff. Cureus 2020, 12, e7541. [CrossRef] [PubMed]

4. Ertmer, P.A. Addressing first-and second-order barriers to change: Strategies for technology integration. Educ. Technol. Res. Dev. 1999, 47, 47-61. [CrossRef]

5. Crawford, J.; Butler-Henderson, K.; Rudolph, J.; Malkawi, B.; Glowatz, M.; Burton, R.; Magni, P.A.; Lam, S. COVID-19: 20 countries' higher education intra-period digital pedagogy responses. J. Appl. Learn. Teach. 2020, 3. [CrossRef]

6. Hodges, C.; Moore, S.; Lockee, B.; Trust, T.; Bond, A. The Difference Between Emergency Remote Teaching and Online Learning. Available online: https:/ / er.educause.edu/articles/2020/3/the-difference-between-emergency-remote-teaching-and-onlinelearning (accessed on 16 December 2020).

7. Wong, J.E.L.; Leo, Y.S.; Tan, C.C. COVID-19 in Singapore-Current Experience: Critical Global Issues That Require Attention and Action. J. Am. Med. Assoc. 2020, 323, 1243-1244. [CrossRef] [PubMed]

8. Weeden, K.A.; Cornwell, B. The Small-World Network of College Classes: Implications for Epidemic Spread on a University Campus. Soc. Sci. 2020, 7, 222-241. [CrossRef]

9. Scott, K.M. Change in university teachers' elearning beliefs and practices: A longitudinal study. Stud. High. Educ. 2014, 41, 582-598. [CrossRef]

10. International Telecommunication Union. 2017. ICT Development Index 2020. Available online: https://www.itu.int/net4/ITUD/idi/2017/index.html\#idi2017economycard-tab\&SGP (accessed on 17 December 2020).

11. Al Gamdi, M.A.; Samarji, A. Perceived Barriers towards e-Learning by Faculty Members at a Recently Established University in Saudi Arabia. Int. J. Inf. Educ. Technol. 2016, 6, 23-28. [CrossRef]

12. Goh, C.F.; Hii, P.K.; Tan, O.K.; Rasli, A. Why do University Teachers use E-Learning Systems? Int. Rev. Res. Open Distrib. Learn. 2020, 21, 136-155. [CrossRef]

13. Martín, S.S.; Jimenez, N.; Rodríguez-Torrico, P.; Piñeiro-Ibarra, I. The determinants of teachers' continuance commitment to e-learning in higher education. Educ. Inf. Technol. 2020, 25, 3205-3225. [CrossRef]

14. Tong, A.; Sainsbury, P.; Craig, J. Consolidated criteria for reporting qualitative research (COREQ): A 32-item checklist for interviews and focus groups. Int. J. Qual. Health Care 2007, 19, 349-357. [CrossRef] [PubMed]

15. Zoom Video Communications Inc. Communications Technology Company. 2016. Available online: https://zoom.us/ (accessed on 7 February 2020).

16. Archibald, M.; Ambagtsheer, R.; Casey, M.G.; Lawless, M. Using Zoom Videoconferencing for Qualitative Data Collection: Perceptions and Experiences of Researchers and Participants. Int. J. Qual. Methods 2018, 18. [CrossRef]

17. Braun, V.; Clarke, V. Using thematic analysis in psychology. Qual. Res. Psychol. 2006, 3, 77-101. [CrossRef]

18. Redmond, P.; Heffernan, A.; Abawi, L.; Brown, A.; Henderson, R. An Online Engagement Framework for Higher Education. Online Learn. 2018, 22. [CrossRef]

19. Wong, M.L.; Koh, D.; Iyer, P.; Seow, A.; Goh, L.G.; Chia, S.E.; Lim, M.K.; Ng, D.; Ong, C.N.; Phua, K.H.; et al. Online Health Education on SARS to University Students during the SARS Outbreak. Int. Electron. J. Health Educ. 2005, 8, $205-217$.

20. Chan, L.; Girish, D.; Hird-Younger, M.; Hunter, M.; Way, K. Equity and Online Learning Survey Results: Research Memo 1, Discovering University Worlds; University of Toronto: Toronto, ON, Canada, 2020.

21. Dhawan, S. Online Learning: A Panacea in the Time of COVID-19 Crisis. J. Educ. Technol. Syst. 2020, 49, 5-22. [CrossRef]

22. Thai, N.T.T.; De Wever, B.; Valcke, M. Face-to-face, blended, flipped, or online learning environment? Impact on learning performance and student cognitions. J. Comput. Assist. Learn. 2020, 36, 397-411. [CrossRef]

23. Njenga, J.K.; Fourie, L.C.H. The myths about e-learning in higher education. Br. J. Educ. Technol. 2008, 41, 199-212. [CrossRef]

24. Parkes, M.; Stein, S.; Reading, C. Student preparedness for university e-learning environments. Internet High. Educ. 2015, 25, 1-10. [CrossRef]

25. Grushka, K.; McLeod, J.H.; Reynolds, R.; Grushka, K. Reflecting upon reflection: Theory and practice in one Australian University teacher education program. Reflect. Pract. 2005, 6, 239-246. [CrossRef]

26. Dixson, M.D. Measuring Student Engagement in the Online Course: The Online Student Engagement Scale (OSE). Online Learn. 2015, 19. [CrossRef]

27. Van Tryon, P.J.S.; Bishop, M. Theoretical foundations for enhancing social connectedness in online learning environments. Distance Educ. 2009, 30, 291-315. [CrossRef]

28. Stone, C.; O'Shea, S. Older, online and first: Recommendations for retention and success. Australas. J. Educ. Technol. 2019, 35, 57-69. [CrossRef]

29. Hando, A. Does Cultural Self-Awareness Alter Instructional Design Decisions? Graduate Thesis, West Virginia University, Morgantown, WV, USA, 2014. 
30. eLearning for Undergraduate Health Professional Education: A Systematic Review Informing a Radical Transformation of Health Workforce Development; Al-Shorbaji, N.; Atun, R.A.; Car, J.; Majeed, A.; Wheeler, E. (Eds.) World Health Organization: Geneva, Switzerland, 2015.

31. Cochrane, T.; Birt, J.; Cowie, N.; Deneen, C.; Goldacre, P.; Narayan, V.; Ransom, L.; Sinfield, D.; Worthington, T. A Collaborative Design Model to Support Hybrid Learning Environments During COVID19. In Proceedings of the ASCILITE 37th International Conference on Innovation, Practice and Research in the Use of Educational Technologies in Tertiary Education, Armidale, Australia, 30 November-1 December 2020.

32. Cheng, M.W.; Chan, C.K.Y. Do university residential experiences contribute to holistic education? J. High. Educ. Policy Manag. 2019, 42, 31-48. [CrossRef]

33. Bergen, N.; Labonté, R. "Everything Is Perfect, and We Have No Problems": Detecting and Limiting Social Desirability Bias in Qualitative Research. Qual. Health Res. 2020, 30, 783-792. [CrossRef]

34. Rivera, E. Using the Flipped Classroom Model in Your Library Instruction Course. Ref. Libr. 2015, 56, 34-41. [CrossRef]

35. Foulger, T.S.; Graziano, K.J.; Schmidt-Crawford, D.; Slykhuis, D.A. Throw me a lifeline: A professional development pro-gram for teacher educators managing the demands from the rapid transition to online teaching. In Teaching, Technology, and Teacher Education During the COVID-19 Pandemic: Stories from the Field; Ferdig, R.E., Baum-Gartner, E., Hartshorne, R., Kaplan-Rakowski, R., Mouza, C., Eds.; Association for the Advancement of Computing in Education: Waynesville, NC, USA, 2020 ; pp. 517-520. 